\title{
Downregulation of NEK11 is associated with drug resistance in ovarian cancer
}

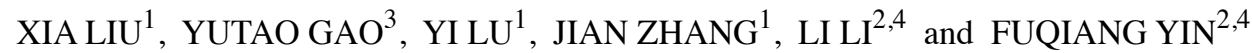 \\ ${ }^{1}$ Center for Translational Medicine and ${ }^{2}$ Medical Scientific Research Centre, Guangxi Medical University, \\ Nanning, Guangxi 530021; ${ }^{3}$ Department of Obstetrics and Gynecology, Beijing Chao-Yang Hospital, \\ Affiliated to Capital Medical University, Chaoyang, Beijing 100020; ${ }^{4}$ Key Laboratory of \\ High-Incidence-Tumor Prevention and Treatment (Guangxi Medical University), \\ Ministry of Education, P.R. China
}

Received April 10, 2014; Accepted June 4, 2014

DOI: $10.3892 /$ ijo.2014.2503

\begin{abstract}
NEKs [NIMA (never in mitosis gene A)-related expressed kinase] are involved in ovarian cancer development and progression, while their association with drug resistance is limited, especially NEK11, and its relationship with drug resistance has never been reported. In this study, on the basis of comprehensive bioinformatic analyses, including mRNA expression according to microarray data, protein/gene interaction, protein-small molecule interaction, annotation of biological process and microRNA-mRNA interaction analysis, we revealed that the NEK11 mRNA was significantly downregulated in 586 cases of ovarian serous cystadenocarcinomas and cisplatin-resistant A2780 ovarian cancer cells, and interacted with 22 proteins and 4 small molecules which all were contributed to drug resistance in ovarian cancer. Furthermore, seven cell cycle-related biological processes were annotated with NEK11, drug resistance and ovarian cancer, suggesting that NEK11 potentially was involved in the drug resistance in ovarian cancer via its regulatory roles in the cell cycle. In addition, among the eight microRNAs predicted to be most strongly targeting NEK11, the majority were involved in drug resistance in ovarian and other cancers. All those results provide a very strong possibility that the notable downregulation of NEK11 in cisplatin-resistant ovarian cancer cells was involved in drug resistance, via its interactions with drug resistance-related genes, proteins, small molecules, microRNAs and biological processes, particularly the cell cycle-related processes. To our knowledge, this is the first report of the association of NEK11 with drug resistance in
\end{abstract}

Correspondence to: Dr Fuqiang Yin, Medical Scientific Research Centre, Guangxi Medical University, 22 Shuangyong Road, Nanning, Guangxi 530021, P.R. China

E-mail: yinfq@mail2.sysu.edu.cn

Key words: NEK11, drug resistance, ovarian cancer, bioinformatics cancer, and it would pave the way for further investigation of the drug resistance-related functions of this gene.

\section{Introduction}

Ovarian cancer is the most lethal cancer of the female reproductive system, with high rate of mortality worldwide. Likewise, ovarian cancer is one of the five leading types of cancer death in women $(1,2)$. In the last 80 years (1930-2010), the overall death rate of ovarian cancer patients declined very slightly (2). The main obstacle to a successful treatment for ovarian cancer is the development of drug resistance to combined chemotherapy (3). Drug resistance results from a variety of factors including decreased cell-associated drugs, altered drug inactivation, increased DNA damage tolerance/repair, increased anti-apoptotic regulator activity and growth factor receptor deregulation $(4,5)$. Besides, abnormal expressions of genes mediated by microRNA regulation also play critical roles in development of drug resistance in ovarian cancer $(6,7)$. However, regardless of mechanisms, abnormal expression of drug resistance-related genes often play important roles in drug resistance (8). Thus, mining and exploring of potentially drug resistance-related genes would be a feasible and reasonable way to meet the challenge of the drug resistance in ovarian cancer (9).

NEK [NIMA (never in mitosis gene A)-related expressed kinase] family is the never-in-mitosis A (NIMA) protein of Aspergillus nidulans, which was first identified by Oakley and Morris in a genetic screen for cell division cycle mutants (10). NEKs have now been identified in a wide range of organisms, and eleven genetically distinct proteins named NEK1 to NEK11 are expressed in humans. The functions of NEKs mainly are involved in the regulation of cell cycle progression, in particular, NEK2, NEK6, NEK7 and NEK9 contribute to the establishment of the microtubule-based mitotic spindle, whereas NEK1, NEK10 and NEK11 have been implicated in the DNA damage response (11). NEKs have been proven to be associated with cancer development and progression, in a cell cycle-dependent manner, and thus the NEKs are considered as potential therapeutic targets in cancer (11-13). 
The association of NEKs with drug resistance in cancer is limited, with only a few studies. For example, NEK2 downregulation may improve the sensitivity of breast cancer cells during chemotherapy treatments (14), and its upregulation may induce drug resistance mainly through activation of efflux drug pumps in myeloma and other cancers (15). NEK4 is downregulated at 8 and/or $24 \mathrm{~h}$ in colon cancer cell lines in response to 5-fluorouracil (16), and its suppression sensitize cancer cells to taxol and vincristine, via regulation on mitosis and microtubule homeostasis (17). In ovarian cancer, we revealed that the upregulation of NEK2 is associated with drug resistance in ovarian cancer, via its direct or indirect interaction with a number of genes, proteins, microRNAs and biological processes (18), and further analysis indicated that the NEK2 expression is regulated by NR2F2 (19). Additionally, NEK1 expression can be induced by paclitaxel (20), NEK4 is identified as a candidate gene as potentiators of cisplatin (21), NEK6 can be affected by paclitaxel through preventing phosphorylation of Thr389 (22), and NEK8 is significantly downregulated in DDP-resistant ovarian cell line IGROV-1 (23). These results indicated that the NEK1, 4, 6 and NEK8 were chemo-treatment related proteins/genes.

However, among all the NEKs, the association of NEK11 with cancer is rare, with one study considering it as a potential tumor suppressor gene (24), and it is significantly downregulated in ovarian cancer, mediated by methylation or mutation $(25,26)$, but its association with drug resistance in cancer has not been reported. In this study, on the basis of comprehensive bioinformatics analyses, we aimed to illustrate the association of NEK11 with drug resistance in ovarian cancer.

\section{Materials and methods}

The microarray data of NEK11 in ovarian cancer tissues was retrieved from the TCGA Ovarian array data deposited in the Oncomine online database (https://www.oncomine.org/ resource/main.html) (27). The microarray data of NEK11 in ovarian cancer cells was retrieved from the Gene Expression Omnibus (GEO) (http://www.ncbi.nlm.nih.gov/geoprofiles/) $(28,29)$. There were three probe sets targeting NEK11, while only two probe sets with significant variability in statistics were kept. Unpaired, two-tailed t-test assuming homogeneity of the variances was performed with Excel software.

The protein/gene interaction analysis was performed using GeneMANIA online tool (http://www.genemania.org/) (30-32). Protein-small molecule/chemical interaction analysis was performed using STITCH 4.0 beta (http://stitch-beta. embl.de/) (33-35) and DrugBank online database $(36,37)$. Annotation of biological process was performed by Coremine Medical online database (http://www.coremine.com/medical/) (38). The microRNAs targeted to the gene were predicted by miRWalk online tool which including 10 prediction tools (DIANAmT, miRanda, miRDB, miRWalk, RNAhybrid, PICTAR4, PICTAR5, PITA, RNA22, Targetscan) (http:// www.umm.uni-heidelberg.de/apps/zmf/mirwalk/) (39).

\section{Results}

NEK11 is significantly downregulated in ovarian cancer tissues and cisplatin-resistant cells. The mRNA expres- sion of NEK11 in ovarian cancer tissues and cells was retrieved from TCGA ovarian array and DataSet Record GDS3754 which have been deposited in Oncomine and GEO online database, respectively. As shown in Fig. 1A and $\mathrm{C}$, compared with the expression in 8 cases of normal ovaries, the NEK11 mRNA was significantly downregulated in 586 cases of ovarian serous cystadenocarcinomas, with a 3.05 -fold change $(P=3.45 E-5)$. Similarly, the expression of the NEK11 in cisplatin-resistant ovarian cancer cells was measured (Fig. 1B and D). As shown in the figure, the mRNA expression of NEK11 was decreased in cisplatinresistant ovarian cancer cells compared with expression in its sensitive counterpart, with at least a 1.8 -fold change $(\mathrm{P}<0.001)$. These results suggested that the downregulation of NEK11 might potentially play crucial roles in development of ovarian cancer and drug resistance.

\section{Prediction and analysis of function based on protein/gene} interactions. Protein/gene-protein/gene interactions performed with GeneMANIA was used to reveal the drug resistance-related functions of NEK11. As shown in Fig. 2, NEK11 had direct interactions with NEK2, MET, JUN, ERBB2, EGFR, AKT1, AKT2, CHEK2, WWOX, IKBKE, ELF3 and MAST2, among those, 10 proteins/genes have been proven to be involved in the regulation of drug resistance in ovarian cancer. NEK2, MET, JUN, ERBB2, EGFR, AKT1, AKT2 and IKBKE are oncogenes associated with drug resistance in ovarian cancer $(18,41-50)$. For example, IKBKE is found to be upregulated in ovarian, breast and prostate cancer, and its upregulation biologically and clinically relevant to the cancer development and progression, as well as the chemoresistance (50). Downregulation of the AKT2 sensitizes the ovarian cancer cells to paclitaxelinduced apoptosis, and inhibits the survivin expression which can induce drug-resistance to paclitaxel (49). NEK2 shared protein domains and had very strong physical interaction with NEK11, and has been proven to be responsible for the development of drug resistance not only in ovarian cancer (18), but also in breast (14) and colorectal cancer (51). CHEK2 and WWOX are the tumor suppressor genes which directly interacted with NEK11. CHEK2 is one of the critical kinases governing cell apoptosis, cell cycle checkpoint and DNA damage repair. In ovarian cancer cells, CHEK2 is degraded at the protein level in response to cisplatin through the ubiquitin-proteasome pathway, suggesting that degradation or decreased expression of CHEK 2 is partially responsible for chemoresistance (52). WWOX suppression by RNA interference reverses platinum resistance in DDP-resistant SKOV3 ovarian cancer cells (53). In addition to the direct interactions, NEK11 indirectly interacted with 15 proteins/genes in the network. Of which, 10 including BRCA1, BRCA2, PTEN, CDKN2A, MLH1, KRAS, MYC, HGF, PMF2 and MLH3 are associated with drug resistance in ovarian cancer (54-63).

Taken together, based on the protein/gene interaction network, total of 28 proteins/genes were identified to be directly/indirectly interacted with NEK11, and of which, 22 were contributed to drug resistance in ovarian cancer. These results strongly supported the idea that NEK11 might associate with drug resistance in ovarian cancer. 
A



B

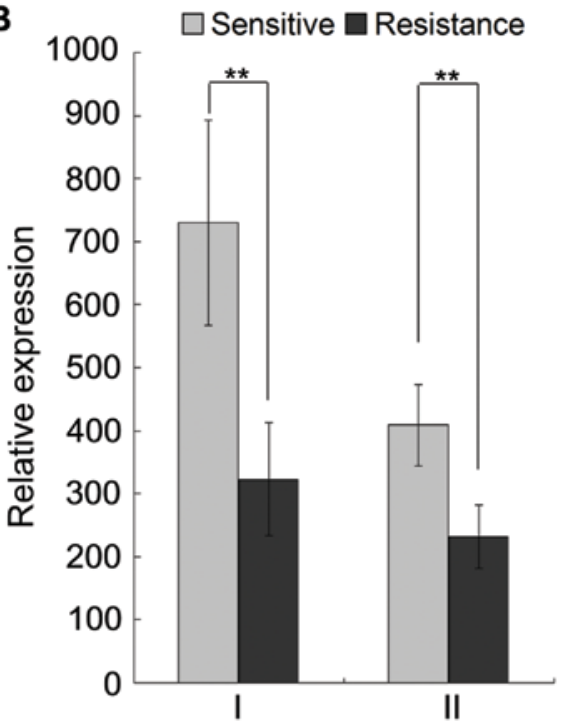

C



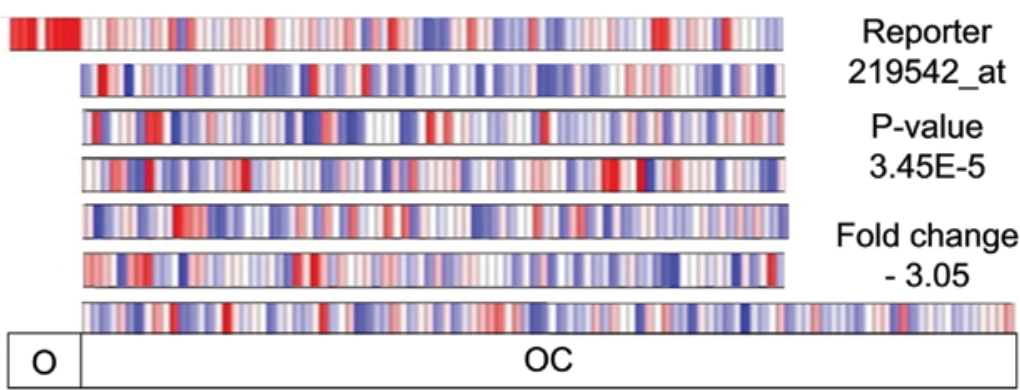

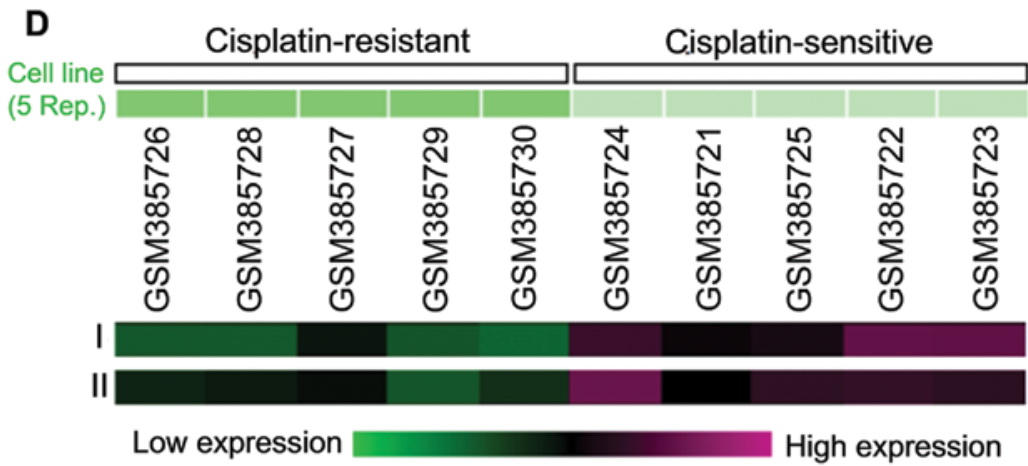

Figure 1. The relative expression of NEK11 in ovarian cancer tissues and cells. (A and C) mRNA expression of NEK11 in 586 cases of ovarian serous cystadenocarcinomas compared with the expression in 8 cases of ovaries used as normal controls $(\mathrm{P}=3.45 \mathrm{E}-5)$, on the basis of TCGA Ovarian array data retrieved from Oncomine online database. The NEK11 expression data in the Oncomine are presented as fold changes, in the present study, the expression of NEK11 in normal ovaries was normalized to 1.0. O, 8 ovaries; OC, 586 ovarian serous cystadenocarcinomas. (B and D) mRNA expression of NEK11 in cisplatin-sensitive and -resistant A2780 ovarian cancer cells (with 5 biological replications each), based on the array data retrieved from the GEO Profiles database (GDS3754). The data have been processed and normalized (40). I, GDS3754/219542_at/NEK11; II, GDS3754/1555082_a_at/NEK11. **Significantly different in statistics.

Prediction and analysis of function based on protein-small molecule/chemical interaction. The protein-small molecule/chemical interaction was performed to further explain the drug resistance-related functions of NEK11 in ovarian cancer. As shown in Table I, five chemicals including CC 243, staurosporine, dasatinib, flavin mononucleotide and dabrafenib were found to interact with NEK11. Except for the CC 243, all the chemicals are associated with drug resistance in ovarian and other cancers. For example, treatment of ovarian cancer cells with staurosporine induces apoptosis in a time-dependent manner
(64), and reduces P-glycoprotein expression and modulates multidrug resistance (65). Dasatinib is an antitumor agent for many solid tumors (66), and can significantly enhance the sensitivity to carboplatin in ovarian cancer cells (67). As for the flavin mononucleotide, a previous study showed that the overexpression of riboflavin kinase increases the levels of flavin mononucleotide and render cell resistance not only to cisplatin but also to hydrogen peroxide and diamide (68), suggesting a role of flavin mononucleotide in regulation of cisplatin resistance. Dabrafenib is an inhibitor of BRAF 


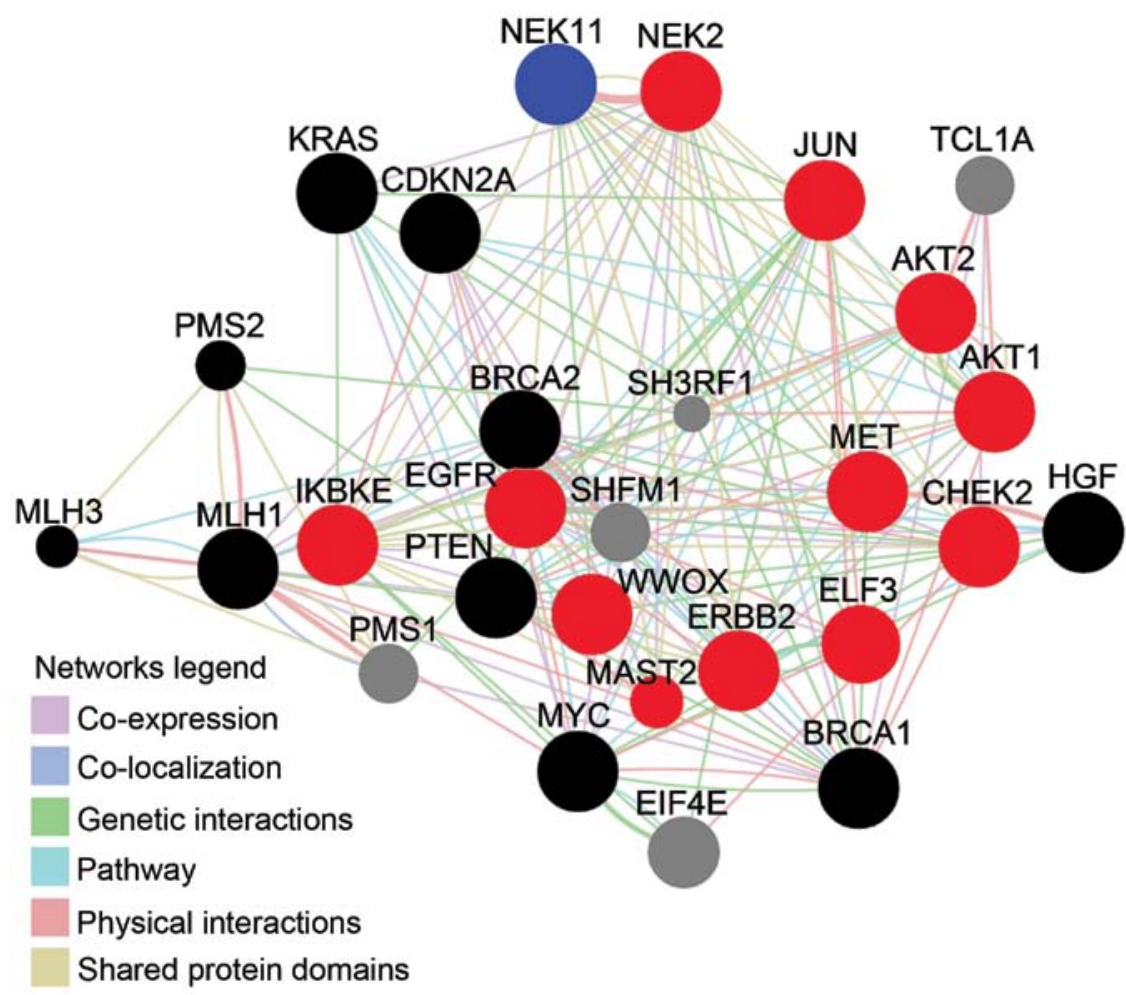

Figure 2. Protein/gene interaction analysis of NEK11 using GeneMANIA online tool. The query in blue is the target NEK11; the queries in red are the proteins/ genes which directly interacted with NEK11; the queries in black are the indirectly interacted proteins/genes which associated with drug resistance in ovarian cancer. The type of interactions between genes/proteins is illustrated as the network legend indicates.

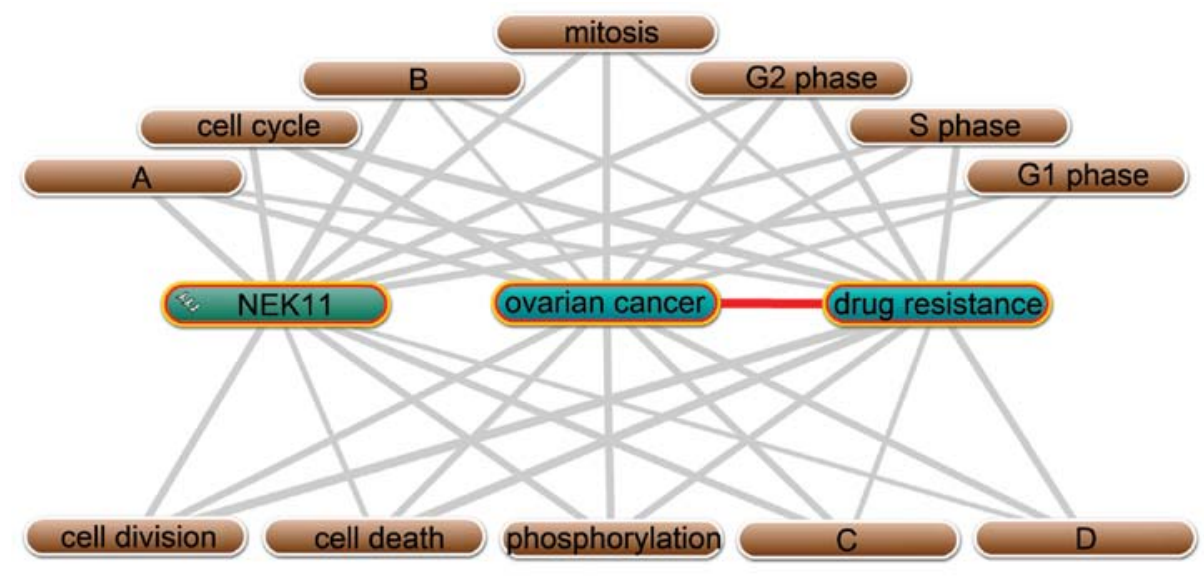
$A$, regulation of cell cycle; $B$, spindle assembly involved in mitosis
C, signal transduction; $\quad$ D, response to DNA damage stimulus

Figure 3. Biological process annotation of NEK11, ovarian cancer and drug resistance $(\mathrm{P}<0.01)$. The input terms were NEK11, ovarian cancer and drug resistance. The line in red indicates the links between input terms; the line in gray indicates the links between the input terms and their annotated biological processes.

leading to constitutive activation of the MAPK signaling pathway $(69,70)$, while the BRAF and MAPK signaling have been proven to play important roles in drug resistance in ovarian cancer (43,71-73).

Prediction and analysis of function based on the annotation of biological processes. The Gene Ontology (GO) (74) provides a valuable source of structured knowledge of protein function in terms of molecular function, biological process, and cellular component. Among other things, each gene may be involved in one or more biological processes (75), and the involvement of a gene in a given biological process can be used to predict the biological role and function of the gene (76). Coremine Medical online database is designed to be used by anyone seeking information on health, medicine, and biology (38), and it analyzed the associations between the genes, biological 
Table I. The small molecules or chemicals interacting with NEK11 and their drug resistance-related functions in cancer.

$\begin{aligned} & \text { Small molecule/ } \\ & \text { chemical }\end{aligned}$
$\begin{gathered}\text { Drug resistance-related associations } \\ \text { of the chemicals in cancer (refs.) }\end{gathered}$

\section{NEK 11}

CC 243

Staurosporine

Associated with multidrug resistance (65)

Dasatinib

Flavin

Involved in drug resistance $(66,67)$

mononucleotide

Dabrafenib Involved in drug resistance $(43,69-73)$

The protein-small molecule/chemical interaction was analyzed using STITCH 4 beta online tool, except that the interaction of Dabrafenib with NEK11 was analyzed by DrugBank online database.

processes and drug resistance as well as ovarian cancer. As shown in Fig. 3, the annotation of biological process indicated there is no direct linkage between NEK11 and ovarian cancer and drug resistance, indicating the limited study among them. Total of 12 biological processes significantly associated with NEK11, ovarian cancer and drug resistance were annotated $(\mathrm{P}<0.01)$ (Fig. 3). Given the intimate relationships of NEK11 with the 12 biological processes, and the intimate relationships of those processes with ovarian cancer and drug resistance, we concluded that NEK11 probably is involved in the regulation of drug resistance in ovarian cancer via its regulatory roles in those biological processes. Among the 12 biological processes, 7 of them including cell cycle, regulation of cell cycle, spindle assembly involved in mitosis, G2 phase, $S$ phase and G1 phase are cell cycle-related processes, indicating that the NEK11 might perform drug resistance-related functions in ovarian cancer mainly via its involvement in the cell cycle.
Functional prediction based on the functionality of the microRNAs that target the gene. MicroRNA-mediated post-transcriptional gene regulation is considered as a significant regulator of many cellular processes, both physiological and pathological $(77,78)$. The microRNAs perform their functions through the regulation on their target genes, and it has been well established that microRNAs represent a class of genes with a great potential for use in diagnostics, prognosis and therapy (79). Therefore, the function of a gene can be predicted based on functionality of the microRNAs that target it (9). A microRNA-mRNA interaction analysis was performed with miRWalk to predict the microRNAs that target NEK11. Using this tool, we identified 443 microRNAs predicted to transcriptionally target NEK11. These results suggesting that the microRNAs might be an important regulation mechanism on NEK11. As shown in Table II, among the top 8 microRNAs most strongly targeted NEK11, 3 microRNAs including miR-21, -590-5p and -149 were shown to be involved in drug resistance in ovarian and other cancers (80-84). For example, the expression of miR-21 is notably upregulated in the paclitaxel-resistant ovarian cancer A2780/taxol cells compared with the parental A2780 cells. Inhibition of miR-21 in A2780/taxol cells decreased the expression of P-gp and HIF- $1 \alpha$ proteins, and increased the sensitivity of the A2780/taxol cells to paclitaxel. These results suggested that miR-21 may be involved in the development of drug resistance and the regulation of MDR1/P-gp expression, at least in part, by targeting HIF-1 $\alpha$ in ovarian cancer cells (80). The other microRNAs did not indicate direct involvement in drug resistance, however, except for the miR-876-5p, they all play important roles in cancer development and progression (as shown in Table II), and might also be involved in the drug resistance. For example, miR-376b controls mTOR inhibition-related autophagy (85), while the autophagy plays an important role in wt p53 and mutant 553 -immediated multidrug resistance in ovarian cancer (86).

Table II. The top 8 microRNAs targeting NEK11, as predicted by microRNA-mRNA interactions and their drug resistancerelated functions in cancer.

\begin{tabular}{|c|c|c|c|c|c|c|c|c|c|c|}
\hline \multirow[b]{2}{*}{ Gene } & \multirow{2}{*}{$\begin{array}{l}\text { MicroRNA } \\
\quad \text { (hsa-) }\end{array}$} & \multicolumn{8}{|c|}{$\begin{array}{l}\text { The microRNA-mRNA } \\
\text { prediction tool }\end{array}$} & \multirow[b]{2}{*}{ Drug resistance-related functions of the microRNAs in cancers (refs.) } \\
\hline & & A & $\mathrm{B}$ & $\mathrm{C}$ & $\mathrm{D}$ & $\mathrm{E}$ & $\mathrm{F}$ & G & $\mathrm{H}$ & \\
\hline \multirow[t]{8}{*}{ NEK11 } & $\operatorname{miR}-376 b$ & 1 & 1 & 1 & 1 & 0 & 1 & 0 & 1 & Controls autophagy (85) \\
\hline & $\operatorname{miR}-21$ & 1 & 1 & 1 & 1 & 0 & 1 & 0 & 1 & Drug resistance (80-82) \\
\hline & $\operatorname{miR}-590-5 p$ & 1 & 1 & 1 & 1 & 0 & 1 & 0 & 1 & Drug resistance (83) \\
\hline & $\operatorname{miR}-876-5 p$ & 1 & 1 & 0 & 1 & 0 & 1 & 0 & 1 & - \\
\hline & $\operatorname{miR}-1255 b$ & 0 & 1 & 1 & 1 & 0 & 1 & 0 & 1 & Tumor suppressor (87) \\
\hline & $\operatorname{miR}-1290$ & 0 & 1 & 1 & 1 & 0 & 1 & 0 & 1 & Impairs cytokinesis and affects the reprogramming of cancer cells (88) \\
\hline & $\operatorname{miR}-149$ & 1 & 1 & 0 & 1 & 0 & 1 & 0 & 1 & Drug resistance and progression-free survival (84) \\
\hline & $\operatorname{miR}-370$ & 1 & 1 & 0 & 1 & 0 & 1 & 0 & 1 & $\begin{array}{l}\text { Tumor suppressor associated with tumor progression and carcinogenesis } \\
(89-91)\end{array}$ \\
\hline
\end{tabular}

A, DIANAmT; B, miRanda; C, miRDB; D, miRWalk; E, RNAhybrid; F, PICTAR5; G, PITA; H, Targetscan. 1, predicted; 0, not predicted. 


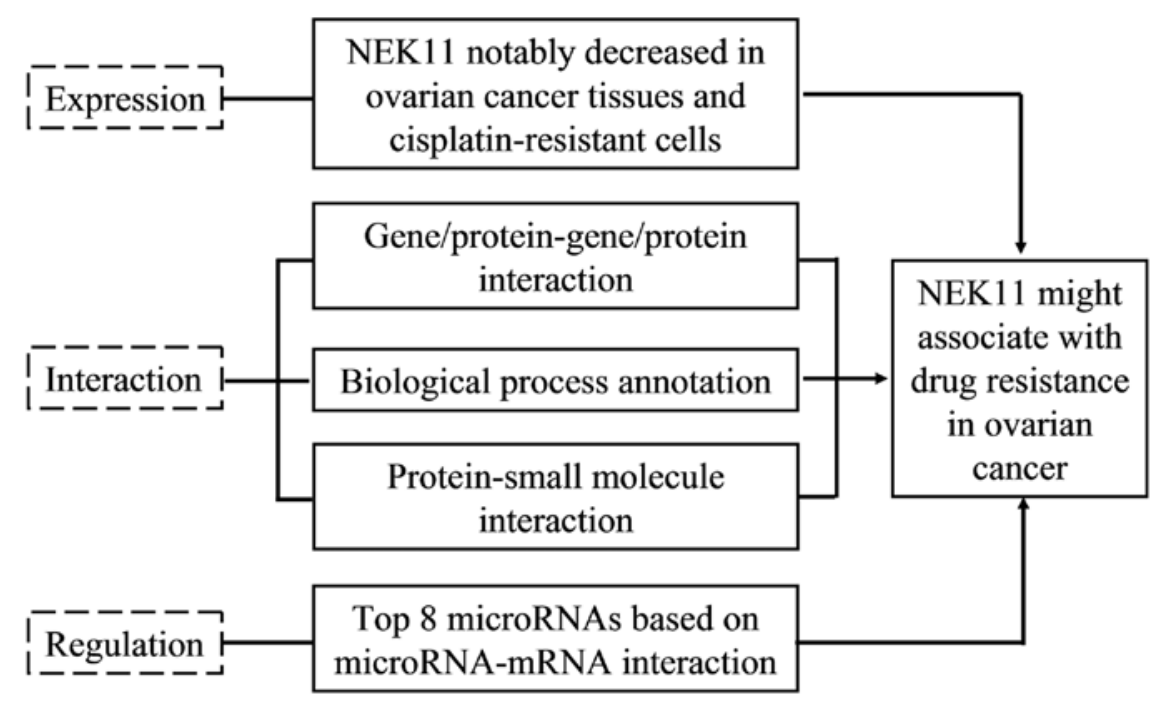

Figure 4. The overall procedure of bioinformatics analyses of NEK11 associated with drug resistance in ovarian cancer.

\section{Discussion}

Functional annotation of proteins/genes is a fundamental problem in the post-genomic era, and determining the functions of proteins encoded in genome sequences represents a major challenge in current biology (92). Experimental determination of protein function is expensive and time-consuming. Thus, computational approaches based on the diverse genomic and proteomic datasets can facilitate more rapid annotation of protein function and guide laboratory experiments $(92,93)$. The computational approaches to gene function prediction have relied on a variety of genomic and proteomic data, at least including usage of microarray expression data (94), protein-protein interaction networks (95), protein-small molecule/chemical interactions (33-35) and the annotation of gene with biological processes (93). Computational methods for inferring protein function, which exploit the context of a protein in cellular networks, can provide both a first hand hint into the functional role of a protein and offer complementary insights to understanding the function of proteins (96). Thus, on the basis of many large-scale databases and networks, gene function prediction based on bioinformatics analysis is a potential, feasible and valuable way for gene function prediction (92). Using the comprehensive bioinformatics analyses, we identified that two genes CCL21 and SPARCL1 are associated with drug resistance in ovarian cancer (9). Similarly, we identified that the upregulation of NEK2 and E2F3 are associated with drug resistance in ovarian cancer and poor prognosis in hepatocellular carcinoma, respectively $(18,97)$

The association of NEK11 with drug resistance in ovarian cancer was analyzed, on the basis of comprehensive bioinformatics analysis (Fig. 4), including microarray data retrieving, protein/gene interaction, protein-small molecule/chemical interaction, biological process annotation and microRNAmRNA interaction. The database/tool/software used in the analysis included GeneMANIA online tool (30-32), Coremine Medical (38), Oncomine online database (27), GEO profiles $(28,29)$, STITCH 4.0 beta (33-35), DrugBank online database
$(36,37)$ and miRWalk $(39)$, which all are regularly used and reliable databases/tools. For example, GeneMANIA is a web-based database and a tool for prediction of gene functions on the basis of multiple networks derived from different genomic or proteomic data/sources (30). With a query gene, GeneMANIA can find a small set of genes that are most likely to share function with that gene based on their interactions with it (32). The GEO at the National Center for Biotechnology Information (NCBI) has emerged as the leading fully public repository for gene expression data, predominantly gene expression data generated by DNA microarray technology (28), and about a billion individual gene expression measurements are stored, submitted by over 1500 laboratories, addressing a wide range of biological phenomena (98). Thus, the protein/ gene functions predicted by these online tools/databases/software were accurate and reliable.

NEK11 mRNA was significantly downregulated in both ovarian cancer tissues and cisplatin-resistant cells (Fig. 1), indicating the potential roles of NEK11 in regulation of drug resistance in ovarian cancer. Protein/gene interaction indicated that among the total 28 proteins/genes which interacted with NEK11, 22 were contributed to drug resistance in ovarian cancer (Fig. 2). Protein-small molecule interaction suggested that among the 5 small molecules/chemicals which interacted with NEK11, 4 were directly/indirectly associated with drug resistance in ovarian and other cancers (Table I). Annotation of biological process indicated that NEK11 probably were involved in the regulation of drug resistance in ovarian cancer via its regulatory roles in 12 biological processes (Fig. 3). MicroRNA-mRNA interaction analysis indicated that among the eight microRNAs most strongly targeting NEK11, the majority were involved in drug resistance in ovarian and other cancers (Table II). All these results provide a very strong possibility that NEK11 is involved in drug resistance in ovarian cancer, via its interactions with a number of genes, proteins, small molecules, microRNAs and related biological processes.

Cell cycle-mediated drug resistance is best described as a relative insensitivity to a chemotherapeutic agent because 
of the position of the cells in the cell cycle. Cell cycle is closely involved in chemosensitivity for combination chemotherapy, and the chemotherapeutic agents correlated with cell cycle events include taxanes, platinum, camptothecin and fluorouracil (99). Cell cycle is closely related to drug resistance in ovarian cancer. For instance, integration of DNA methylation and gene expression reveals specific platinum resistance related signaling pathways in ovarian cancer, which include cell growth-promoting pathways PI3K/Akt and cell cycle progression (40). Besides, curcumin and cisplatin or oxaliplatin can induce cell cycle inhibition (100), and cell cycle synchronization can reverse taxol resistance of human ovarian cancer cell lines (101). In addition, comprehensive bioinformatics analysis indicates that 15 TSGs perform their drug resistance-related functions through 5 pathways including cell cycle (8). Annotation of NEK11 with ovarian cancer and drug resistance generated 12 biological processes, of which, 7 were cell cycle-related processes. Thus, given the important roles of NEK11 in regulation of cell cycle $(11,12)$, the important roles of the cell cycle in drug resistance (99), and the close linkages between NEK11 and drug resistance (Fig. 3), we concluded that the NEK11 might be associated with drug resistance in ovarian cancer via regulation of the cell cycle.

Taken together, for the first time, we illustrated that downregulation of NEK11 in drug resistant cells might contribute to drug resistance, via their interactions with a number of drug resistance-related genes, proteins, small molecules and microRNAs, and probably through regulation of the cell cycle. This study set the stage for further investigation into the drug resistant-related functions of NEK11, in ovarian and other cancers.

\section{Acknowledgements}

The project was supported by the National Natural Science Foundation of China (Grant No. 81302283), Youth Science Foundation of Guangxi Medical University (No. GXMUYSF201205), and China Postdoctoral Science Foundation (No. 2014M552535XB).

\section{References}

1. Siegel R, Naishadham D and Jemal A: Cancer statistics, 2013. CA Cancer J Clin 63: 11-30, 2013.

2. Siegel R, Ma J, Zou Z and Jemal A: Cancer statistics, 2014. CA Cancer J Clin 64: 9-29, 2014.

3. Cannistra SA: Cancer of the ovary. N Engl J Med 351: 2519-2529, 2004.

4. Sorrentino A, Liu CG, Addario A, Peschle C, Scambia G and Ferlini C: Role of microRNAs in drug-resistant ovarian cancer cells. Gynecol Oncol 111: 478-486, 2008.

5. Johnson SW, Ozols RF and Hamilton TC: Mechanisms of drug resistance in ovarian cancer. Cancer 71: 644-649, 1993.

6. Parikh A, Lee C, Peronne J, Marchini S, Baccarini A, Kolev V, Romualdi C, Fruscio R, Shah H, Wang F, Mullokandov G, Fishman D, D'Incalci M, Rahaman J, Kalir T, Redline RW, Brown BD, Narla G and DiFeo A: microRNA-181a has a critical role in ovarian cancer progression through the regulation of the epithelial-mesenchymal transition. Nat Commun 5: 2977, 2014.

7. Li H, Xu H and Shen H: microRNA-106a modulates cisplatin sensitivity by targeting PDCD4 in human ovarian cancer cells. Oncol Lett 7: 183-188, 2014.

8. Yin F, Liu X, Li D, Wang Q, Zhang W and Li L: Tumor suppressor genes associated with drug resistance in ovarian cancer (review). Oncol Rep 30: 3-10, 2013.
9. Yin F, Liu X, Li D, Wang Q, Zhang W and Li L: Bioinformatic analysis of chemokine (C-C motif) ligand 21 and SPARC-like protein 1 revealing their associations with drug resistance in ovarian cancer. Int J Oncol 42: 1305-1316, 2013.

10. Oakley BR and Morris R: A mutation in Aspergillus nidulans that blocks the transition from interphase to prophase. J Cell Biol 96: 1155-1158, 1983.

11. Fry AM, O'Regan L, Sabir SR and Bayliss R: Cell cycle regulation by the NEK family of protein kinases. J Cell Sci 125: 4423-4433, 2012.

12. Malumbres $\mathbf{M}$ and Barbacid $\mathrm{M}$ : Cell cycle kinases in cancer. Curr Opin Genet Dev 17: 60-65, 2007.

13. Bou Zgheib N, Xiong Y, Marchion DC, Bicaku E, Chon HS, Stickles XB, Sawah EA, Judson PL, Hakam A and GonzalezBosquet $\mathrm{J}$ : The $\mathrm{O}$-glycan pathway is associated with in vitro sensitivity to gemcitabine and overall survival from ovarian cancer. Int J Oncol 41: 179-188, 2012.

14. Lee J and Gollahon L: Nek2-targeted ASO or siRNA pretreatment enhances anticancer drug sensitivity in triplenegative breast cancer cells. Int J Oncol 42: 839-847, 2013.

15. Zhou W, Yang Y, Xia J, Wang H, Salama ME, Xiong W, Xu H, Shetty S, Chen T and Zeng Z: NEK2 induces drug resistance mainly through activation of efflux drug pumps and is associated with poor prognosis in myeloma and other cancers. Cancer Cell 23: 48-62, 2013.

16. De Angelis PM,Svendsrud DH, Kravik KL and Stokke T: Cellular response to 5-fluorouracil (5-FU) in 5-FU-resistant colon cancer cell lines during treatment and recovery. Mol Cancer 5: 20, 2006.

17. Doles J, Hemann MT, Doles J and Hemann M: Nek4 status differentially alters sensitivity to distinct microtubule poisons. Cancer Res 70: 1033, 2010.

18. Liu X, Gao Y, Lu Y, Zhang J, Li L and Yin F: Upregulation of NEK2 is associated with drug resistance in ovarian cancer. Oncol Rep 31: 745-754, 2014.

19. Hawkins SM, Loomans HA, Wan YW, Ghosh-Choudhury T, Coffey D, Xiao W, Liu Z, Sangi-Haghpeykar H and Anderson ML: Expression and functional pathway analysis of nuclear receptor NR2F2 in ovarian cancer. J Clin Endocrinol Metab 98: E1152-E1162, 2013.

20. Bani MR, Nicoletti MI, Alkharouf NW, Ghilardi C, Petersen D, Erba E, Sausville EA, Liu ET and Giavazzi R: Gene expression correlating with response to paclitaxel in ovarian carcinoma xenografts. Mol Cancer Ther 3: 111-121, 2004.

21. Arora S, Bisanz KM, Peralta LA, Basu GD, Choudhary A, Tibes R and Azorsa DO: RNAi screening of the kinome identifies modulators of cisplatin response in ovarian cancer cells. Gynecol Oncol 118: 220-227, 2010.

22. Le XF, Hittelman WN, Liu J, McWatters A, Li C, Mills GB and Bast RC Jr: Paclitaxel induces inactivation of p70 S6 kinase and phosphorylation of Thr421 and Ser424 via multiple signaling pathways in mitosis. Oncogene 22: 484-497, 2003.

23. Cheng L, Lu W, Kulkarni B, Pejovic T, Yan X, Chiang JH, Hood L, Odunsi K and Lin B: Analysis of chemotherapy response programs in ovarian cancers by the next-generation sequencing technologies. Gynecol Oncol 117: 159-169, 2010.

24. Bozic I, Antal T, Ohtsuki H, Carter H, Kim D, Chen S, Karchin R, Kinzler KW, Vogelstein B and Nowak MA: Accumulation of driver and passenger mutations during tumor progression. Proc Natl Acad Sci USA 107: 18545-18550, 2010.

25. Moniz L, Dutt P, Haider N and Stambolic V: Nek family of kinases in cell cycle, checkpoint control and cancer. Cell Div 6: $18,2011$.

26. Kashuba V, Dmitriev AA, Krasnov GS, Pavlova T, Ignatjev I, Gordiyuk VV, Gerashchenko AV, Braga EA, Yenamandra SP, Lerman M, Senchenko VN and Zabarovsky E: NotI microarrays: novel epigenetic markers for early detection and prognosis of high grade serous ovarian cancer. Int J Mol Sci 13: 13352-13377, 2012.

27. Rhodes DR, Yu J, Shanker K, Deshpande N, Varambally R, Ghosh D, Barrette T, Pandey A and Chinnaiyan AM: ONCOMINE: a cancer microarray database and integrated datamining platform. Neoplasia 6: 1-6, 2004.

28. Barrett T and Edgar R: Mining microarray data at NCBI's Gene Expression Omnibus (GEO). Methods Mol Biol 338: 175-190, 2006

29. Edgar R, Domrachev M and Lash AE: Gene Expression Omnibus: NCBI gene expression and hybridization array data repository. Nucleic Acids Res 30: 207-210, 2002.

30. Mostafavi S, Ray D, Warde-Farley D, Grouios C and Morris Q: GeneMANIA: a real-time multiple association network integration algorithm for predicting gene function. Genome Biol 9 (Suppl 1): S4, 2008. 
31. Warde-Farley D, Donaldson SL, Comes O, Zuberi K, Badrawi R, Chao P, Franz M, Grouios C, Kazi F, Lopes CT, Maitland A, Mostafavi S, Montojo J, Shao Q, Wright G, Bader GD and Morris Q: The GeneMANIA prediction server: biological network integration for gene prioritization and predicting gene function. Nucleic Acids Res 38: W214-W220, 2010.

32. Zuberi K, Franz M, Rodriguez H, Montojo J, Lopes CT, Bader GD and Morris Q: GeneMANIA prediction server 2013 update. Nucleic Acids Res 41: W115-W222, 2013.

33. Kuhn M, Szklarczyk D, Franceschini A, von Mering C, Jensen LJ and Bork P: STITCH 3: zooming in on protein-chemical interactions. Nucleic Acids Res 40: D876-D880, 2012.

34. Kuhn M, Szklarczyk D, Franceschini A, Campillos M, von Mering C, Jensen LJ, Beyer A and Bork P: STITCH 2: an interaction network database for small molecules and proteins. Nucleic Acids Res 38: D552-D556, 2010.

35. Kuhn M, von Mering C, Campillos M, Jensen LJ and Bork P: STITCH: interaction networks of chemicals and proteins Nucleic Acids Res 36: D684-D688, 2008.

36. Wishart DS, Knox C, Guo AC, Cheng D, Shrivastava S, Tzur D, Gautam B and Hassanali M: DrugBank: a knowledgebase for drugs, drug actions and drug targets. Nucleic Acids Res 36: D901-D906, 2008.

37. Law V, Knox C, Djoumbou Y, Jewison T, Guo AC, Liu Y, Maciejewski A, Arndt D, Wilson M, Neveu V, Tang A, Gabriel G, Ly C, Adamjee S, Dame ZT, Han B, Zhou Y and Wishart DS: DrugBank 4.0: shedding new light on drug metabolism. Nucleic Acids Res 42: D1091-D1097, 2014

38. de Leeuw N, Dijkhuizen T, Hehir-Kwa JY, et al: Diagnostic interpretation of array data using public databases and internet sources. Hum Mutat 33: 930-940, 2012.

39. Dweep H, Sticht C, Pandey P and Gretz N: miRWalk - database: prediction of possible miRNA binding sites by 'walking' the genes of three genomes. J Biomed Inform 44: 839-847, 2011

40. Li M, Balch C, Montgomery JS, Jeong M, Chung JH, Yan P, Huang TH, Kim S and Nephew KP: Integrated analysis of DNA methylation and gene expression reveals specific signaling pathways associated with platinum resistance in ovarian cancer. BMC Med Genomics 2: 34, 2009.

41. Tang MK, Zhou HY, Yam JW and Wong AS: c-Met overexpression contributes to the acquired apoptotic resistance of nonadherent ovarian cancer cells through a cross talk mediated by phosphatidylinositol 3-kinase and extracellular signal-regulated kinase 1/2. Neoplasia 12: 128-138, 2010.

42. Pan B, Yao KS, Monia BP, Dean NM, McKay RA, Hamilton TC and O'Dwyer PJ: Reversal of cisplatin resistance in human ovarian cancer cell lines by a c-jun antisense oligodeoxynucleotide (ISIS 10582): evidence for the role of transcription factor overexpression in determining resistant phenotype. Biochem Pharmacol 63: 1699-1707, 2002

43. Mansouri A, Ridgway LD, Korapati AL, Zhang Q, Tian L, Wang Y, Siddik ZH, Mills GB and Claret FX: Sustained activation of JNK/p38 MAPK pathways in response to cisplatin leads to Fas ligand induction and cell death in ovarian carcinoma cells. J Biol Chem 278: 19245-19256, 2003

44. Smith V, Hobbs S, Court W, Eccles S, Workman P and Kelland LR: ErbB2 overexpression in an ovarian cancer cell line confers sensitivity to the HSP90 inhibitor geldanamycin. Anticancer Res 22: 1993-1999, 2002.

45. Zhou BP, Hu MC, Miller SA, Yu Z, Xia W, Lin SY and Hung MC: HER-2/neu blocks tumor necrosis factor-induced apoptosis via the Akt/NF-kappaB pathway. J Biol Chem 275: 8027-8031, 2000.

46. Qiu L, Di W, Jiang Q, Scheffler E, Derby S, Yang J, Kouttab N, Wanebo H, Yan B and Wan Y: Targeted inhibition of transient activation of the EGFR-mediated cell survival pathway enhances paclitaxel-induced ovarian cancer cell death. Int J Oncol 27: $1441-1448,2005$

47. Sen T, Sen N, Brait M, Begum S, Chatterjee A, Hoque MO, Ratovitski E and Sidransky D: DeltaNp63alpha confers tumor cell resistance to cisplatin through the AKT1 transcriptional regulation. Cancer Res 71: 1167-1176, 2011.

48. Xing H, Weng D, Chen G, Tao W, Zhu T, Yang X, Meng L, Wang S, Lu Y and Ma D: Activation of fibronectin/PI-3K/Akt2 leads to chemoresistance to docetaxel by regulating survivin protein expression in ovarian and breast cancer cells. Cancer Lett 261: 108-119, 2008.

49. Weng D, Song X, Xing H, Ma X, Xia X, Weng Y, Zhou J, Xu G, Meng L, Zhu T, Wang S and Ma D: Implication of the Akt2/survivin pathway as a critical target in paclitaxel treatment in human ovarian cancer cells. Cancer Lett 273: 257-265, 2009.
50. Guan H, Zhang H, Cai J, Wu J, Yuan J, Li J, Huang Z and Li M: IKBKE is over-expressed in glioma and contributes to resistance of glioma cells to apoptosis via activating NF-кB. J Pathol 223: 436-445, 2011.

51. Suzuki K, Kokuryo T, Senga T, Yokoyama Y, Nagino M and Hamaguchi M: Novel combination treatment for colorectal cancer using Nek2 siRNA and cisplatin. Cancer Sci 101: 1163-1169, 2010.

52. Zhang P, Gao W, Li H, Reed E and Chen F: Inducible degradation of checkpoint kinase 2 links to cisplatin-induced resistance in ovarian cancer cells. Biochem Biophys Res Commun 328 $567-572,2005$

53. Liu YY, Li L, Li DR, Zhang W and Wang Q: Suppression of WWOX gene by RNA interference reverses platinum resistance acquired in SKOV3/SB cells. Zhonghua Fu Chan Ke Za Zhi 43: 854-858, 2008 (In Chinese).

54. Yang D, Khan S, Sun Y, Hess K, Shmulevich I, Sood AK and Zhang W: Association of BRCA1 and BRCA2 mutations with survival, chemotherapy sensitivity, and gene mutator phenotype in patients with ovarian cancer. JAMA 306: 1557-1565, 2011

55. Zhou C, Smith JL and Liu J: Role of BRCA1 in cellular resistance to paclitaxel and ionizing radiation in an ovarian cancer cell line carrying a defective BRCA1. Oncogene 22: 2396-2404, 2003.

56. Lee S, Choi EJ, Jin C and Kim DH: Activation of PI3K/Akt pathway by PTEN reduction and PIK3CA mRNA amplification contributes to cisplatin resistance in an ovarian cancer cell line. Gynecol Oncol 97: 26-34, 2005.

57. Wu H, Cao Y, Weng D, Xing H, Song X, Zhou J, Xu G, Lu Y, Wang S and Ma D: Effect of tumor suppressor gene PTEN on the resistance to cisplatin in human ovarian cancer cell lines and related mechanisms. Cancer Lett 271: 260-271, 2008.

58. Kawakami Y,Hama S, Hiura M, Nogawa T, Chiba T, Yokoyama T, Takashima S, Tajiri H, Eguchi K, Nagai N, Shigemasa K, Ohama K, Kurisu K and Heike Y: Adenovirus-mediated p16 gene transfer changes the sensitivity to taxanes and Vinca alkaloids of human ovarian cancer cells. Anticancer Res 21: 2537-2545, 2001.

59. Plumb JA, Strathdee G, Sludden J, Kaye SB and Brown R: Reversal of drug resistance in human tumor xenografts by 2'-deoxy-5-azacytidine-induced demethylation of the hMLH1 gene promoter. Cancer Res 60: 6039-6044, 2000.

60. Ratner ES, Keane FK, Lindner R, Tassi RA, Paranjape T, Glasgow M, Nallur S, Deng Y, Lu L, Steele L, Sand S, Muller RU, Bignotti E, Bellone S, Boeke M, Yao X, Pecorelli S, Ravaggi A, Katsaros D, Zelterman D, Cristea MC, Yu H, Rutherford TJ, Weitzel JN, Neuhausen SL, Schwartz PE, Slack FJ, Santin AD and Weidhaas JB: A KRAS variant is a biomarker of poor outcome, platinum chemotherapy resistance and a potential target for therapy in ovarian cancer. Oncogene 31: 4559-4566, 2012.

61. Vogt U, Falkiewicz B, Bielawski K, Bosse U and Schlotter CM: Relationship of c-myc and erbB oncogene family gene aberrations and other selected factors to ex vivo chemosensitivity of ovarian cancer in the modified ATP-chemosensitivity assay. Acta Biochim Pol 47: 157-164, 2000.

62. Bardella C, Dettori D, Olivero M, Coltella N, Mazzone M and Di Renzo MF: The therapeutic potential of hepatocyte growth factor to sensitize ovarian cancer cells to cisplatin and paclitaxel in vivo. Clin Cancer Res 13: 2191-2198, 2007.

63. Xiao X, Melton DW and Gourley C: Mismatch repair deficiency in ovarian cancer - molecular characteristics and clinical implications. Gynecol Oncol 132: 506-512, 2014.

64. Gregory-Bass RC, Olatinwo M, Xu W, Matthews R, Stiles JK, Thomas K, Liu D, Tsang B and Thompson WE: Prohibitin silencing reverses stabilization of mitochondrial integrity and chemoresistance in ovarian cancer cells by increasing their sensitivity to apoptosis. Int J Cancer 122: 1923-1930, 2008

65. Sampson KE, Wolf CL and Abraham I: Staurosporine reduces P-glycoprotein expression and modulates multidrug resistance. Cancer Lett 68: 7-14, 1993.

66. Gnoni A, Marech I, Silvestris N, Vacca A and Lorusso V: Dasatinib: an anti-tumour agent via Src inhibition. Curr Drug Targets 12: 563-578, 2011

67. Jinawath N, Vasoontara C, Jinawath A, Fang X, Zhao K, Yap KL, Guo T, Lee CS, Wang W, Balgley BM, Davidson B, Wang TL and Shih Ie M: Oncoproteomic analysis reveals co-upregulation of RELA and STAT5 in carboplatin resistant ovarian carcinoma. PLoS One 5: e11198, 2010.

68. Hirano G, Izumi H, Yasuniwa Y, Shimajiri S, Ke-Yong W, Sasagiri Y, Kusaba H, Matsumoto K, Hasegawa T, Akimoto M, Akashi $\mathrm{K}$ and Kohno $\mathrm{K}$ : Involvement of riboflavin kinase expression in cellular sensitivity against cisplatin. Int J Oncol 38: 893-902, 2011. 
69. Hertzman Johansson C and Egyhazi Brage S: BRAF inhibitors in cancer therapy. Pharmacol Ther 142: 176-182, 2014.

70. Bucheit AD and Davies MA: Emerging insights into resistance to BRAF inhibitors in melanoma. Biochem Pharmacol 87: 381-389, 2014

71. Janku F, Tsimberidou AM, Garrido-Laguna I, Wang X, Luthra R, Hong DS, Naing A, Falchook GS, Moroney JW, Piha-Paul SA, Wheler JJ, Moulder SL, Fu S and Kurzrock R: PIK3CA mutations in patients with advanced cancers treated with $\mathrm{PI} 3 \mathrm{~K} /$ AKT/mTOR axis inhibitors. Mol Cancer Ther 10: 558-565, 2011

72. Janku F, Wheler JJ, Westin SN, Moulder SL, Naing A, Tsimberidou AM, Fu S, Falchook GS, Hong DS, GarridoLaguna I, Luthra R, Lee JJ, Lu KH and Kurzrock R: PI3K/ AKT/mTOR inhibitors in patients with breast and gynecologic malignancies harboring PIK3CA mutations. J Clin Oncol 30: 777-782, 2012.

73. Fister S, Gunthert AR, Aicher B, Paulini KW, Emons G and Grundker C: GnRH-II antagonists induce apoptosis in human endometrial, ovarian, and breast cancer cells via activation of stress-induced MAPKs $\mathrm{p} 38$ and JNK and proapoptotic protein Bax. Cancer Res 69: 6473-6481, 2009.

74. Gene Ontology consortium http://www.geneontology.org.

75. Gamberoni G, Storari S and Volinia S: Finding biological process modifications in cancer tissues by mining gene expression correlations. BMC Bioinformatics 7: 6, 2006.

76. Lagreid A, Hvidsten TR, Midelfart H, Komorowski J and Sandvik AK: Predicting gene ontology biological process from temporal gene expression patterns. Genome Res 13: 965-979, 2003.

77. Kloosterman WP and Plasterk RH: The diverse functions of microRNAs in animal development and disease. Dev Cell 11: 441-450, 2006.

78. Croce CM and Calin GA: miRNAs, cancer, and stem cell division. Cell 122: 6-7, 2005.

79. Tili E, Michaille JJ, Gandhi V, Plunkett W, Sampath D and Calin GA: miRNAs and their potential for use against cancer and other diseases. Future Oncol 3: 521-537, 2007.

80. Xie Z, Cao L and Zhang J: miR-21 modulates paclitaxel sensitivity and hypoxia-inducible factor-1alpha expression in human ovarian cancer cells. Oncol Lett 6: 795-800, 2013

81. Li B, Ren S, Li X, Wang Y, Garfield D, Zhou S, Chen X, Su C, Chen M, Kuang P, Gao G, He Y, Fan L, Fei K, Zhou C and Schmit-Bindert G: MiR-21 overexpression is associated with acquired resistance of EGFR-TKI in non-small cell lung cancer. Lung Cancer 83: 146-153, 2014.

82. Yang SM, Huang C, Li XF, Yu MZ, He Y and Li J: miR-21 confers cisplatin resistance in gastric cancer cells by regulating PTEN. Toxicology 306: 162-168, 2013.

83. Watson JA, Bryan K, Williams R, Popov S, Vujanic G, Coulomb A, Boccon-Gibod L, Graf N, Pritchard-Jones K and O'Sullivan M: miRNA profiles as a predictor of chemoresponsiveness in Wilms' tumor blastema. PLoS One 8: e53417, 2013.

84. Berghmans T, Ameye L, Willems L, Paesmans M, Mascaux C, Lafitte JJ, Meert AP, Scherpereel A, Cortot AB, Cstoth I, Dernies T, Toussaint L, Leclercq N and Sculier JP: Identification of microRNA-based signatures for response and survival for non-small cell lung cancer treated with cisplatin-vinorelbine $A$ ELCWP prospective study. Lung Cancer 82: 340-345, 2013.

85. Korkmaz G, le Sage C, Tekirdag KA, Agami R and Gozuacik D: miR-376b controls starvation and mTOR inhibition-related autophagy by targeting ATG4C and BECN1. Autophagy 8: 165-176, 2012.
86. Kong D, Ma S, Liang B, Yi H, Zhao Y, Xin R, Cui L, Jia L and Liu X: The different regulatory effects of p53 status on multidrug resistance are determined by autophagy in ovarian cancer cells. Biomed Pharmacother 66: 271-278, 2012.

87. Hidaka H, Seki N, Yoshino H, Yamasaki T, Yamada Y, Nohata N, Fuse M, Nakagawa M and Enokida H: Tumor suppressive microRNA-1285 regulates novel molecular targets: aberrant expression and functional significance in renal cell carcinoma. Oncotarget 3: 44-57, 2012.

88. Wu J, Ji X, Zhu L, Jiang Q, Wen Z, Xu S, Shao W, Cai J, Du Q, Zhu Y and Mao J: Up-regulation of microRNA-1290 impairs cytokinesis and affects the reprogramming of colon cancer cells. Cancer Lett 329: 155-163, 2013.

89. Yungang W, Xiaoyu L, Pang T, Wenming L and Pan X: miR-370 targeted FoxM1 functions as a tumor suppressor in laryngeal squamous cell carcinoma (LSCC). Biomed Pharmacother 68: 149-154, 2014.

90. Fan C, Liu S, Zhao Y, Han Y, Yang L, Tao G, Li Q and Zhang L: Upregulation of miR-370 contributes to the progression of gastric carcinoma via suppression of FOXO1. Biomed Pharmacother 67: 521-526, 2013.

91. Feng Y1, Wang L, Zeng J, Shen L, Liang X, Yu H, Liu S, Liu Z, Sun Y, Li W, Chen C and Jia J: Fork head box M1 is overexpressed in Helicobacter pylori-induced gastric carcinogenesis and is negatively regulated by hsa-miR-370. Mol Cancer Res 11: 834-844, 2013.

92. Sharan R, Ulitsky I and Shamir R: Network-based prediction of protein function. Mol Syst Biol 3: 88, 2007.

93. Phuong $\mathrm{T}$ and Nhung N: Predicting gene function using similarity learning. BMC Genomics 14 (Suppl 4): S4, 2013.

94. Stuart JM, Segal E, Koller D and Kim SK: A gene-coexpression network for global discovery of conserved genetic modules. Science 302: 249-255, 2003.

95. Uetz P, Giot L, Cagney G, Mansfield TA, Judson RS, Knight JR, Lockshon D, Narayan V, Srinivasan M, Pochart P, Qureshi-Emili A, Li Y, Godwin B, Conover D, Kalbfleisch T, Vijayadamodar G, Yang M, Johnston M, Fields S and Rothberg JM: A comprehensive analysis of protein-protein interactions in Saccharomyces cerevisiae. Nature 403: 623-627, 2000.

96. Janga S, Díaz-Mejía JJ and Moreno-Hagelsieb G: Network-based function prediction and interactomics: the case for metabolic enzymes. Metab Eng 13: 1-10, 2011.

97. Zeng X, Yin F, Liu X, Xu J, Xu Y, Huang J, Nan Y and Qiu X: Upregulation of E2F transcription factor 3 is associated with poor prognosis in hepatocellular carcinoma. Oncol Rep 31: 1139-1146, 2014.

98. Barrett T and Edgar R: Gene expression omnibus: microarray data storage, submission, retrieval, and analysis. Methods Enzymol 411: 352-369, 2006.

99. Shah MA and Schwartz GK: Cell cycle-mediated drug resistance: an emerging concept in cancer therapy. Clin Cancer Res 7: 2168-2181, 2001 .

100. Montopoli M, Ragazzi E, Froldi G and Caparrotta L: Cell-cycle inhibition and apoptosis induced by curcumin and cisplatin or oxaliplatin in human ovarian carcinoma cells. Cell Prolif 42: 195-206, 2009.

101. Wang X, Pan L, Mao N, Sun L, Qin X and Yin J: Cell-cycle synchronization reverses Taxol resistance of human ovarian cancer cell lines. Cancer Cell Int 13: 77, 2013. 